\title{
QUEEN'S
UNIVERSITY
BELFAST
}

\section{Evaluation of the extreme traffic load effects on the Forth Road Bridge using image analysis of traffic data}

Micu, E. A., Malekjafarian, A., OBrien, E. J., Quilligan, M., McKinstray, R., Angus, E., Lydon, M., \& Catbas, F. N. (2019). Evaluation of the extreme traffic load effects on the Forth Road Bridge using image analysis of traffic data. Advances in Engineering Software, 137, [102711]. https://doi.org/10.1016/j.advengsoft.2019.102711

Published in:

Advances in Engineering Software

Document Version:

Peer reviewed version

Queen's University Belfast - Research Portal:

Link to publication record in Queen's University Belfast Research Portal

Publisher rights

Copyright 2019 Elsevier.

This manuscript is distributed under a Creative Commons Attribution-NonCommercial-NoDerivs License

(https://creativecommons.org/licenses/by-nc-nd/4.0/), which permits distribution and reproduction for non-commercial purposes, provided the author and source are cited.

\section{General rights}

Copyright for the publications made accessible via the Queen's University Belfast Research Portal is retained by the author(s) and / or other copyright owners and it is a condition of accessing these publications that users recognise and abide by the legal requirements associated with these rights.

Take down policy

The Research Portal is Queen's institutional repository that provides access to Queen's research output. Every effort has been made to ensure that content in the Research Portal does not infringe any person's rights, or applicable UK laws. If you discover content in the Research Portal that you believe breaches copyright or violates any law, please contact openaccess@qub.ac.uk. 


\title{
Manuscript Details
}

\section{Manuscript number}

Title
ADES_2018_1187

Evaluation of the extreme traffic load effects on the Forth Road Bridge using image analysis of traffic data

Article type

Research Paper

\begin{abstract}
This paper proposes a novel technique to estimate site-specific characteristic maximum traffic load effects on the Forth Road suspension Bridge (FRB). Congestion represents a critical loading state for long-span bridges and congested traffic data such as car/truck mix, vehicle weights and inter-vehicle gaps are not generally simultaneously available. Most Weigh-in-Motion (WIM) systems used worldwide to collect traffic data are not reliable in congested conditions. A closed-circuit television camera and image processing techniques were used here to collect five months of bridge traffic data on the FRB. Frames extracted from videos are automatically analysed by applying standard image processing algorithms. Hence vehicle lengths and relative positions on the bridge are extracted. An on-site WIM database with free-flowing traffic data is used to establish a statistical correlation between vehicle lengths and their weights. This correlation is applied to infer weights from the vehicle lengths recorded on the bridge. Congestion is modelled for northbound traffic by collapsing the inter-vehicle gaps to minimum values. The axial force in the main cable of the bridge is calculated using the corresponding influence line. The characteristic maximum values for axial force are evaluated for 75 -year and 1000 -year return periods.
\end{abstract}

Keywords

\section{Corresponding Author \\ Corresponding Author's Institution}

Order of Authors

Suggested reviewers bridge; congestion; Forth Road Bridge; image data; long-span; traffic loading; site-specific; vehicle length.

E. Alexandra Micu

University College Dublin

E. Alexandra Micu, Abdollah Malekjafarian, Eugene OBrien, Michael Quilligan, Ross McKinstray, Ewan Angus, Myra Lydon, Fikret Catbas

Michael Beer, Amir H. Alavi, Colin Caprani, Xin Ruan, Mohammad Noori, Andrzej Nowak

\section{Submission Files Included in this PDF}

File Name [File Type]

Letter to editor.pdf [Cover Letter]

Highlights.docx [Highlights]

Manuscript.docx [Manuscript File]

To view all the submission files, including those not included in the PDF, click on the manuscript title on your EVISE Homepage, then click 'Download zip file'. 
University College Dublin, Newstead,

Belfield, Dublin 4, Ireland

$\mathrm{T}+35317163201$

$\mathrm{F}+35317163297$
An Coláiste Ollscoile, Baile Átha Cliath, Newstead,

Belfield, Baile Átha Cliath 4, Eire

www.ucd.ie/eacollege/csee/

$6^{\text {th }}$ December, 2018

\section{RE: "Evaluation of the extreme traffic load effects on the Forth Road Bridge using image analysis of traffic data"}

Dear Editor,

I am pleased to attach herewith a paper on the traffic load evaluation on the Forth Road suspension Bridge. This paper is submitted at the request of Prof. Topping and we would appreciate it if he could handle the review.

Long-span bridge loading is governed by congestion but, unfortunately, WIM technologies do not work in such conditions so there are no databases of vehicle locations and weights available. Cameras can be used to determine vehicle lengths and the mixes of cars and trucks that occur during congestion but the associated vehicle weights are not available.

In this paper, we test the concept of using cameras to measure vehicle lengths and estimating weights from the lengths. It is shown that the image data along with weights estimated from vehicle lengths give accurate estimates for the effects of traffic loading. To our knowledge, this is the first time that researchers have published a method of extracting traffic data using a camera and image processing techniques. We feel this has great potential for future use in gathering traffic data on long-span bridges in congested situations using images. I look forward to reading the comments of your reviewers.

Yours sincerely

cthiar

Elena-Alexandra Micu

$\mathrm{PhD}$ Researcher,

School of Civil Engineering,

University College Dublin,

E: alexandra.micu@ucdconnect.ie

P: +35317163231 
Research highlights

- Congestion governs traffic loading on long-span bridges - this method overcomes the fact that weights cannot be measured in congested conditions.

- Finding extreme traffic load effects on the Forth Road suspension Bridge using only vehicle lengths from image data.

- The weights of vehicles are inferred from their lengths based on statistical correlation.

- The site-specific characteristic load is estimated for 75 and 1000-year return period.

- The influence of inter-vehicle gaps and lane changing on effectiveness of the approach is considered. 


\title{
Evaluation of the extreme traffic load effects on the Forth Road Bridge using
}

\section{image analysis of traffic data}

\section{E. Alexandra Micu1*, Abdollah Malekjafarian², Eugene J. OBrien³, Michael Quilligan, ${ }^{1,4}$ Ross} McKinstray $^{5}$, Ewan Angus 5 , Myra Lydon', F. Necati Catbas ${ }^{7}$

${ }^{1} \mathrm{Ph} . \mathrm{D}$. Researcher, School of Civil Engineering, University College Dublin, Dublin, Ireland

${ }^{2}$ Postdoctoral Researcher, School of Civil Engineering, University College Dublin, Dublin, Ireland

${ }^{3}$ Professor, School of Civil Engineering and Earth Institute, University College Dublin, Dublin, Ireland

${ }^{4}$ Lecturer, School of Engineering, University of Limerick, Limerick, Ireland

${ }^{5}$ Engineer, Amey Consulting, Forth Road Bridge, Administration Building, South Queensferry, Scotland

${ }^{6}$ Postdoctoral Researcher, School of Natural and Built Environment, Queen's University Belfast, David Keir Building, Belfast, Northern Ireland

${ }^{7}$ Professor, Civil Infrastructure Technologies for Resilience and Safety, University of Central Florida, Orlando, United States

* Corresponding author (alexandra.micu@ucdconnect.ie). Postal address: School of Civil Engineering, Newstead building, University College Dublin, Belfield, Dublin 4, Ireland. Phone number: +3531 7163231

\begin{abstract}
:
This paper proposes a novel technique to estimate site-specific characteristic maximum traffic load effects on the Forth Road suspension Bridge (FRB). Congestion represents a critical loading state for long-span bridges and congested traffic data such as car/truck mix, vehicle weights and inter-vehicle gaps are not generally simultaneously available. Most Weigh-in-Motion (WIM) systems used worldwide to collect traffic data are not reliable in congested conditions. A closed-circuit television camera and image processing techniques were used here to collect five months of bridge traffic data on
\end{abstract}


the FRB. Frames extracted from videos are automatically analysed by applying standard image processing algorithms. Hence vehicle lengths and relative positions on the bridge are extracted. An onsite WIM database with free-flowing traffic data is used to establish a statistical correlation between vehicle lengths and their weights. This correlation is applied to infer weights from the vehicle lengths recorded on the bridge. Congestion is modelled for northbound traffic by collapsing the inter-vehicle gaps to minimum values. The axial force in the main cable of the bridge is calculated using the corresponding influence line. The characteristic maximum values for axial force are evaluated for 75 year and 1000-year return periods.

Keywords: bridge, congestion, Forth Road Bridge, image data, influence lines, long-span, traffic loading, site-specific, vehicle length.

\section{Introduction}

Accurate assessment of bridge reliability requires a knowledge of traffic loading and the capacity of the bridge to carry load. In conventional safety assessment, bridge safety is ensured if load effects (bending moments, shear forces etc.) are less than the corresponding resistances. While resistance has been the subject of many studies [1-5], loading, especially traffic loading, has received relatively little attention [6-9].

Congestion is the critical loading condition for traffic on long-span bridges [10-15]. In congested conditions, the effect of heavy traffic has much more impact than in free-flowing conditions due to the higher percentage of heavy vehicles on the bridge and the smaller gaps between them [16]. This makes the measurement of loading a challenge because of insufficient data about the gaps between vehicles and the vehicle (car/truck) mix. Weigh-in-motion (WIM) is the most widespread method utilized to survey traffic and collect traffic weight data $[17,18]$. Unfortunately, most WIM technologies do not work in congested traffic [19]. Therefore, traffic data recorded in such conditions are not reliable. 
Vehicles move between lanes as traffic becomes jammed, so the car/truck mix recorded in freeflowing traffic is no longer valid in congested conditions.

A considerable amount of literature has been published on traffic loading of long-span bridges [20-27]. Some researchers have attempted to explain the relationship between driver behaviour [28-32] and different types of congested traffic [33-36] that may occur. Treiber et al. [37] model congestion using microsimulation which is a process that allocates individual driver behaviour parameters to individual vehicles. This method is extensively applied to simulate the traffic loading on long-span bridges $[7,15$, 38, 39]. Caprani [39] uses traffic microsimulation to calibrate a traffic congestion model for long-run simulations since the classic traffic microsimulation is available for short-run simulations only. The response of vehicles to different conditions of traffic is modelled by OBrien et al. [25] using microsimulation software. The aim of their work is to anticipate the car/truck mix on the bridge in congested traffic situations. A car-following model is applied by OBrien et al. [19] to identify the critical traffic loading conditions for single lane long-span bridges. According to their results, the critical loading case may result from any one of several types of congestion that may occur on the bridge and not consistently from any particular one. Caprani et al. [34] expand the single lane approach to multi-lane traffic microsimulation, introducing a lane changing model. Queues of traffic with constant values for inter-vehicle gaps (axle to axle distances) are proposed in some studies [8, 10-12] to model the traffic loading on long-span bridges. However, most of the studies cited above use WIM measurements (vehicle weights and lengths and vehicle mix) recorded in free-flowing traffic conditions. Considering that WIM sensors accurately record traffic data only at high-speed, there is no data available to calibrate the parameters of congested traffic models.

Computer vision and image processing approaches are being used increasingly for traffic data surveys [40-42]. These approaches are effective for vehicle detection [43-45] and classification in different traffic conditions [46-48]. They are also useful for the evaluation of traffic density [42] and vehicle 
speed $[49,50]$. Driver behaviour in different weather and traffic conditions can also be analysed using video data [51]. Buckland et al. [52] and Nowak et al. [13] use traffic video data in bridge traffic loading studies. Ricketts and Page [53] investigate the car/truck mix within and between lanes, both in free-flowing and in congested traffic, using video data recorded at several sites in the United Kingdom. OBrien et al. [25] use traffic video data to observe the driver behaviour and the car/truck mix as traffic changes from free-flowing to congestion. They use these observations to manually calibrate a microsimulation model. In the recent past, the authors $[54,55]$ have proposed the use of image traffic data and image processing approaches to collect traffic data in congested states. Using standard image processing approaches, valuable information such as vehicle lengths and car/truck mix can be extracted from images. However, images do not provide any direct information on vehicle weights.

This paper proposes an innovative approach for traffic load effect evaluation on the FRB using only vehicle lengths obtained from images. Five months of traffic image data and almost one year of WIM measurements collected on site are used to illustrate the approach. Standard image analysis techniques are applied to process the images and extract the lengths of the vehicles passing over the bridge. A statistical correlation between length and weight is developed by analysing the free-flowing WIM data records. This relationship is used to infer weights from the vehicle lengths provided by the images. The traffic load effects on the FRB, as a result of congested traffic, are calculated using influence lines. A site-specific characteristic load is estimated for 75-year and 1000-year return periods and compared with Eurocode Load Model 1 and the AASHTO HL93 model.

\section{Data collection and site description}

The traffic travelling on a suspension bridge in Central Scotland is the subject of this study. The traffic crossing this bridge has been captured as video data and WIM records. The site, equipment and the collected data are described in the following sub-sections. 
The Forth Road Bridge (FRB) connects Edinburgh to the north of Scotland at North Queensferry. It has provided a road link across the River Forth since September 1964. The bridge carries a two-lane roadway, a walkway and a cycle track in each direction. The FRB stretches $2.5 \mathrm{~km}$ with more than 1 $\mathrm{km}$ main span and with towers around $94 \mathrm{~m}$ above deck level - Figure 1. General traffic was prohibited on the bridge from September 2017 and the FRB became part of a Public Transport Corridor after being in general service for 53 years.

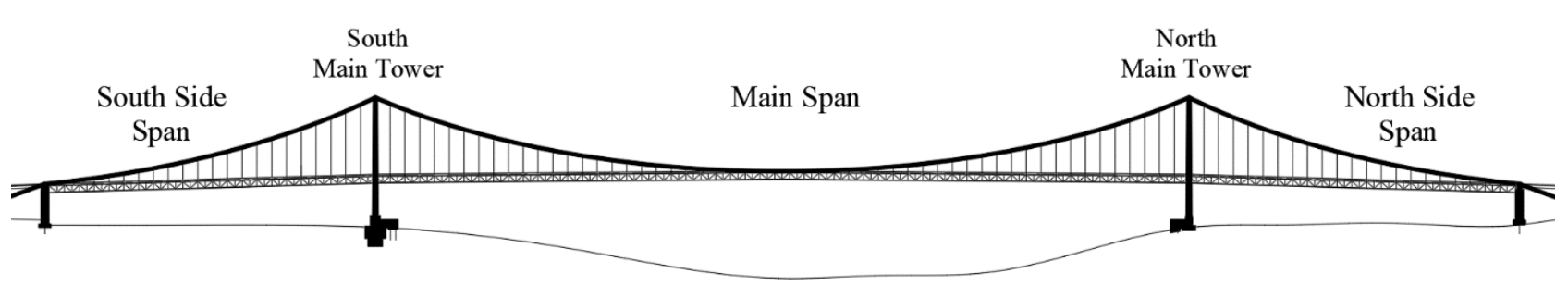

Figure 1: FRB longitudinal elevation.

\subsection{Traffic monitoring system}

A CCTV system has been used to monitor traffic on the bridge. The monitoring system incorporates an Internet Protocol camera (IP camera), a network video recorder (NVR) and a Power-over-Ethernet (PoE) power supply unit. Figure 2 shows the components of the monitoring system. The camera is suitable for an outdoor environment and has multiple features such as pan/tilt/zoom (PTZ) control and a 20x optical zoom. It captures high quality images up to 25 frames per second. The embedded infrared-cut filter (IR) improves day time recording, switching from day to night mode for continuous functionality. The PoE unit provides data connection and electric power through one cable. The system requires a Network Video Recorder (NVR) to control the recording and video management. The NVR features a wide range of functions, including recording, capture, playback and backup. 


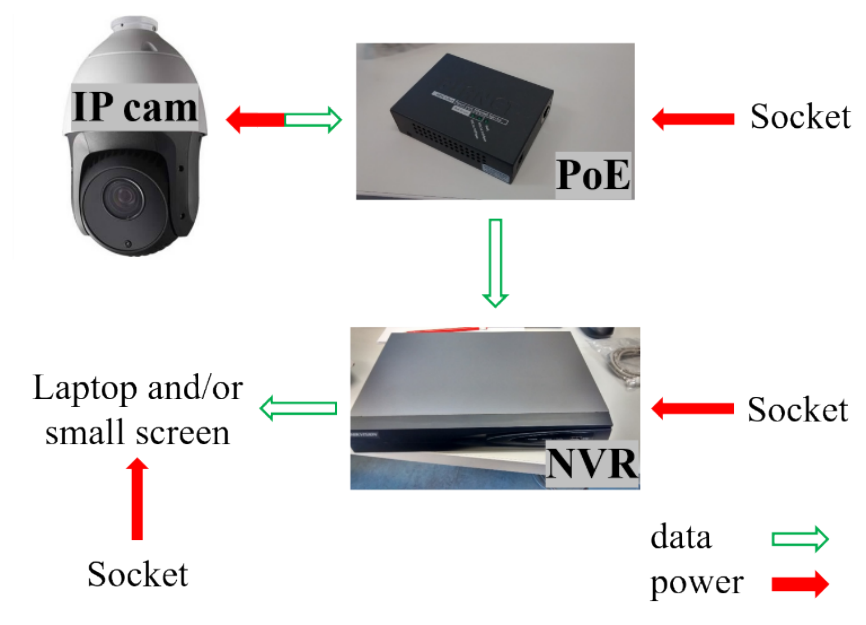

a)

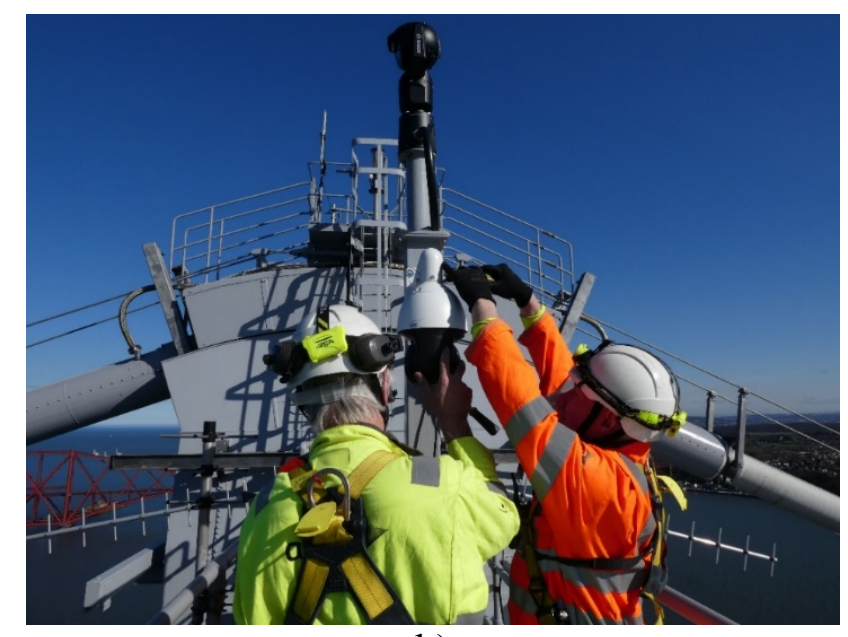

b)

Figure 2: CCTV system: a) scheme; b) camera installation on the bridge tower.

\subsection{WIM data}

Free-flowing WIM data, used in this study, was recorded from $20^{\text {th }}$ July 2016 to $22^{\text {nd }}$ June 2017 using an existing WIM system at the FRB site. The WIM sensors, installed in the pavement in all four lanes, recorded more than 20 million vehicles in that year. The system is located approximately $20 \mathrm{~m}$ south of the bridge, allowing the registration of all vehicles that enter and exit the bridge.

Quality issues in data recorded by WIM systems are reported in some studies [56]. Thus, the accuracy of WIM data used in this work was checked by applying diverse cleaning criteria [57]. Approximately 2 million suspicious records were filtered out from the database and only the remaining data were used.

\subsection{Video data}

The monitoring system described in Section 2.2 was mounted on the bridge on the south tower in 2017 and surveyed the traffic from April to August. Videos of the traffic on both the south and northbound lanes from south side span were recorded with a nominal time interval of 1.0 second. Figure 3 shows the camera elevation and the length of traffic on the bridge captured by it. Five months of video data, in one direction only (northbound), are used in this study. As most of the vehicles cross the bridge during the day and the video data recorded during the night time are of low quality, videos recorded from $10 \mathrm{pm}$ to 5 am were removed from the data set. The data corresponding to rush hours $(7-8$ am 
and $3-6 \mathrm{pm}$ ) were also removed since many passenger cars travel at this time of the day. It was judged that the traffic load at these times is likely to be less. Frames were extracted from the remaining videos for data analysis.

\section{South Main Tower}

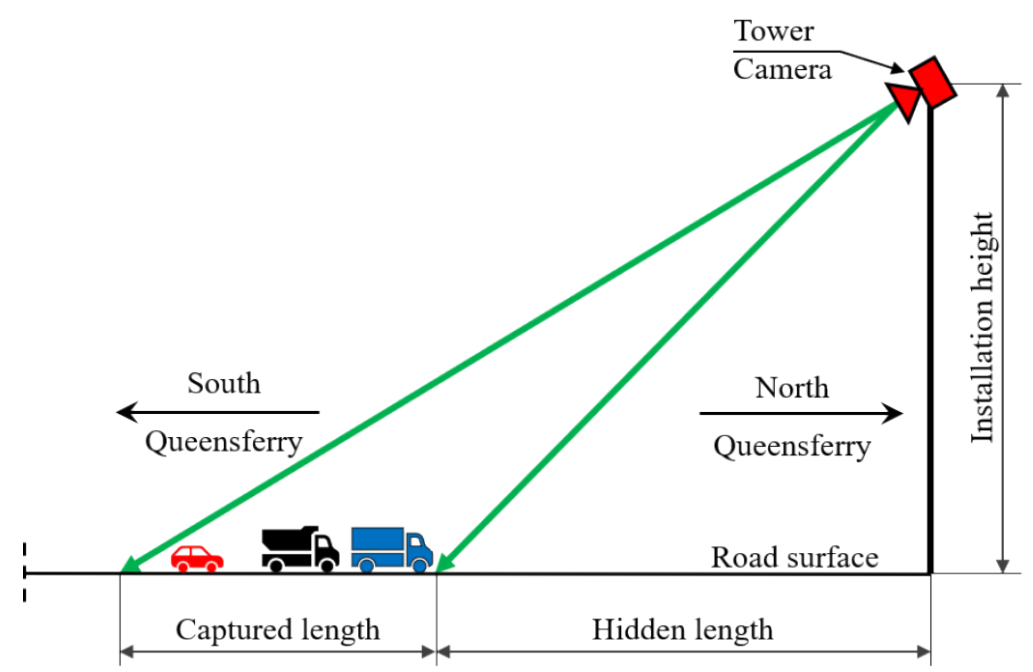

Figure 3. Camera elevation view.

\section{Image data}

Figure 4(a) is an example of a colour image analysed in this study. The camera captures the data as a digital image which is represented numerically as a tensor. For each pixel of the image, the intensities of the three primary colours are stored using numbers in the $[0,255]$ range. In Figure 4(a), a bright rectangle encloses a small area in the bottom left hand corner (truck cabin) and the intensities of the pixels in this area are numerically represented in Figure 4(b). The higher red intensity values indicate the dominance of the red colour channel over the green and blue channels. 


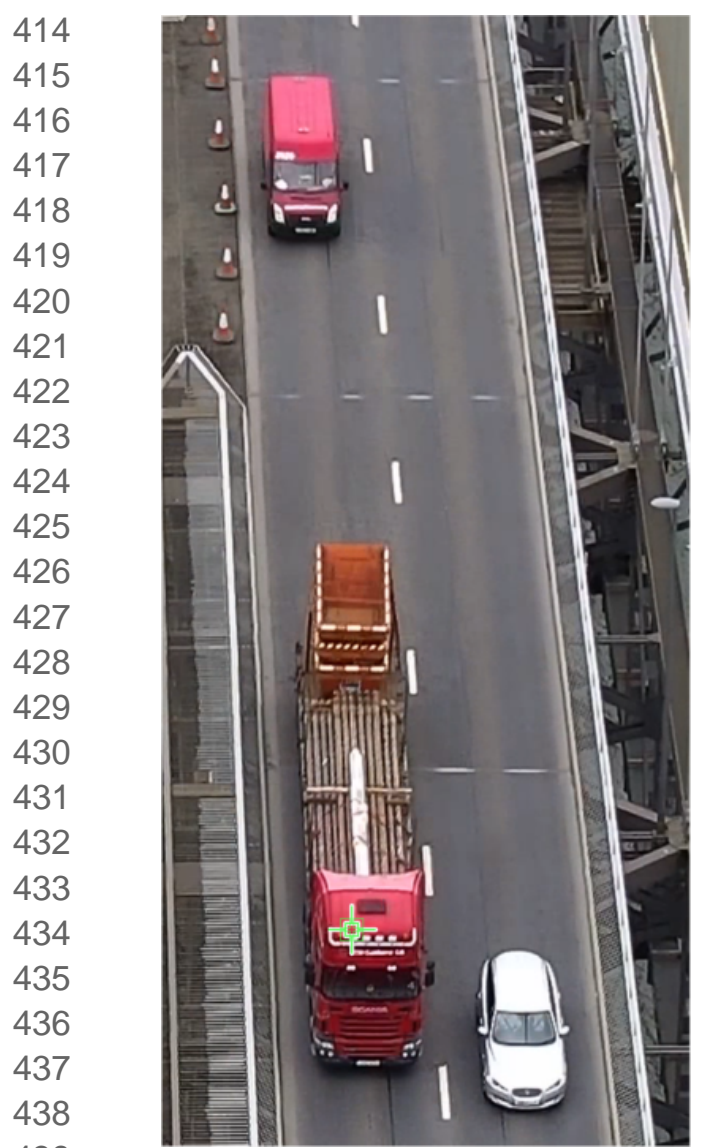

a)

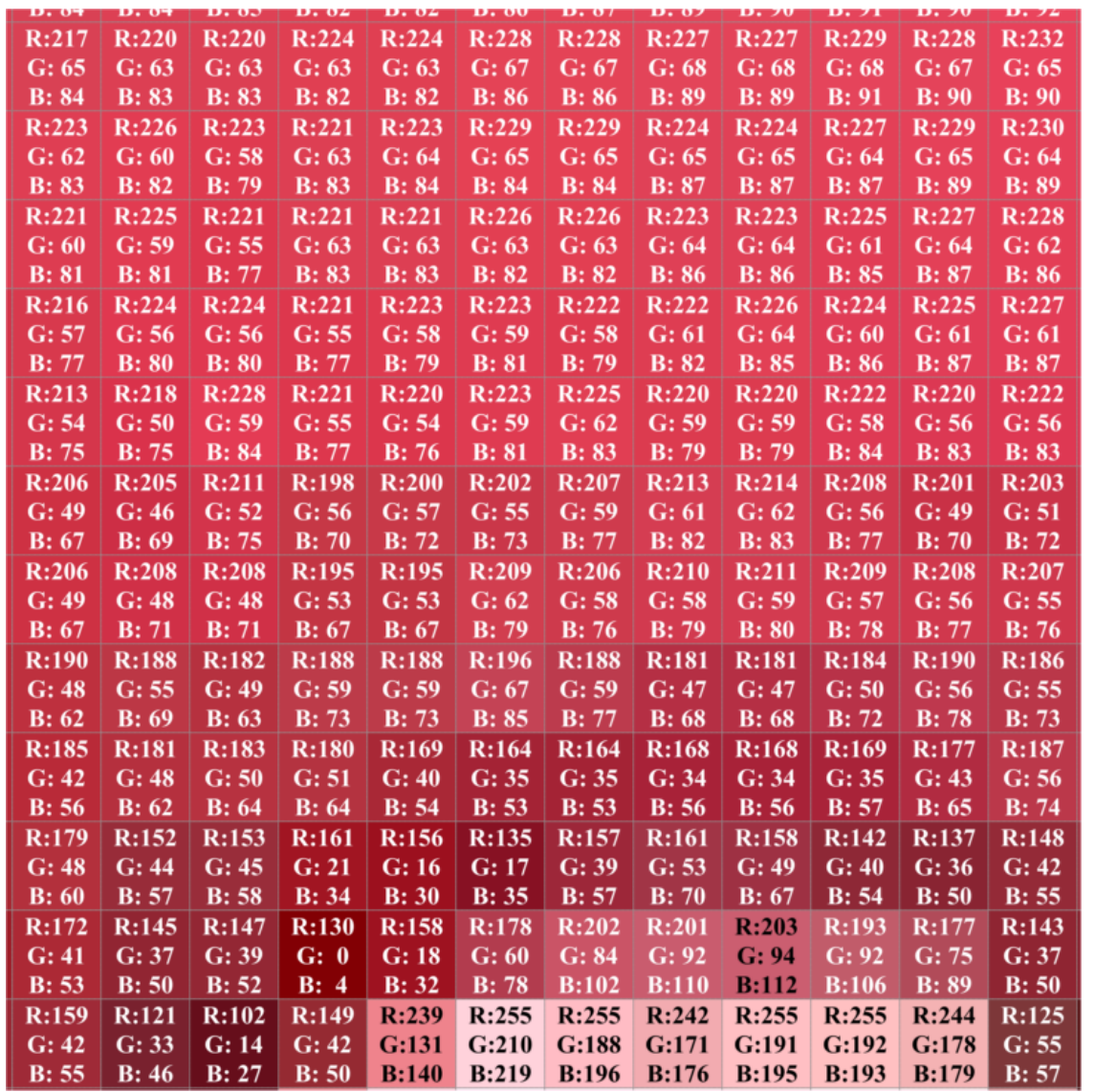

b)

Figure 4. Image representation: a) colour image - area of interest; b) colour channels: red, green and blue (R, G, B).

\subsection{Vehicle lengths in images}

This research seeks to address the problem of bridge load assessment using vehicle length data only.

Thresholding [58] and morphological reconstruction [59] are the conventional procedures applied to images to extract traffic data $[46,49,60]$. Thresholding is an elementary method that uses one constant threshold value to divide a digital image into its background and foreground. In this research, adaptive thresholding [61] is implemented to improve the automated image processing algorithm developed by the authors in [55]. This consists of a statistical examination of the values of intensity in each pixel neighbourhood to determine the local threshold. The colour image is divided into individual colour channels which are displayed in greyscale. Each colour channel is individually analysed, and the results obtained after processing are summed. Morphological reconstruction methods are then applied to establish the contour of the vehicles. Finally, each vehicle contour is enclosed in a rectangle whose dimensions are used to size the vehicle. To validate the results, the rectangles can be overlain on the 
colour image. Figure 5 shows three examples of vehicles identified in images. It can be seen to be approximate, often over-estimating vehicle length to a modest degree. In a random check of 400 pictures, the method has been found to have a $95 \%$ identification rate.

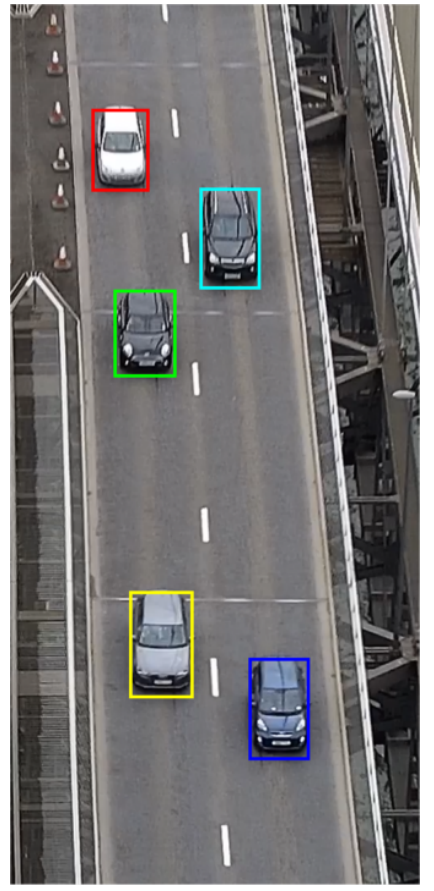

a)

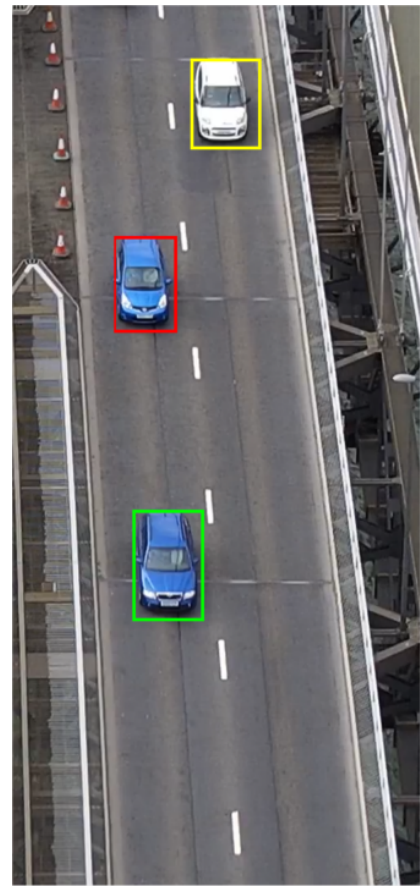

b)

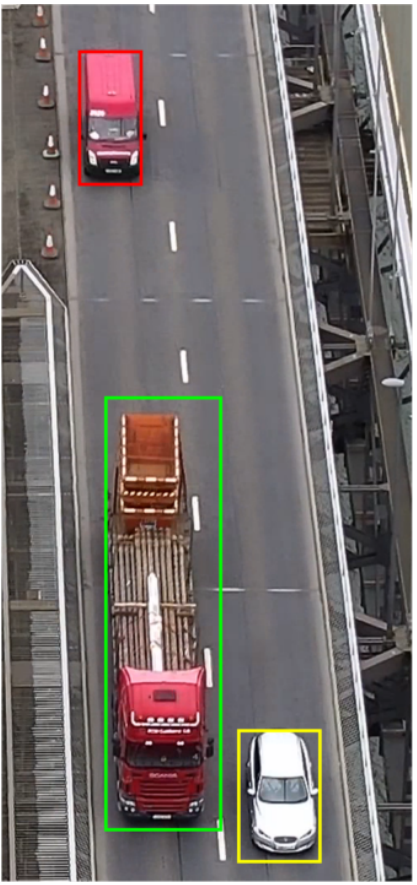

c)

Figure 5. Vehicles in images: a) Example 1; b) Example 2;

\section{c) Example 3.}

Extremes of wind, sun and fog introduce errors in the image data, as illustrated in Figure 6. In strong sunlight (Figure 6(a)) shadows are mistaken for parts of the object/vehicle. Strong wind (Figure 6(b)) causes relative movement between the camera/tower and the bridge deck, resulting in blurred images. Fog also results in low-quality images - Figure 6(c). in these conditions, vehicles can be identified with longer or shorter lengths. One vehicle is not detected in Figure 6(c) while an area of the road is misidentified as a vehicle. More examples of errors related to the weather conditions are illustrated in [55] and [62]. For reasons of poor weather conditions, ten days out of 140 days of data were removed to prevent large number of errors. 


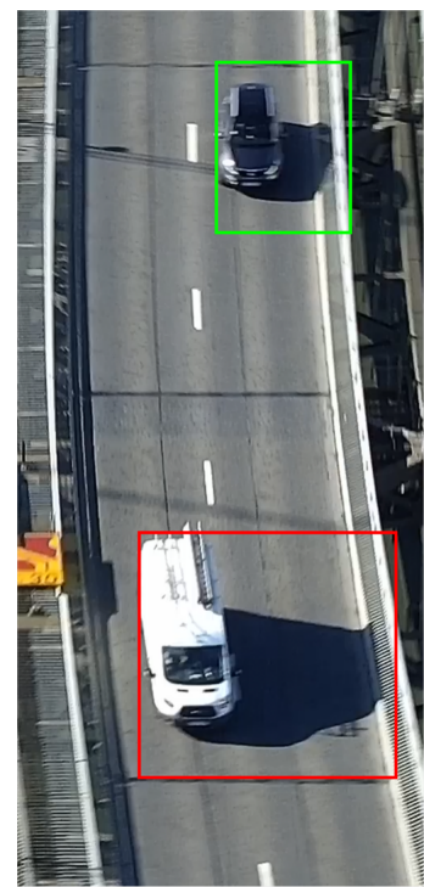

a)

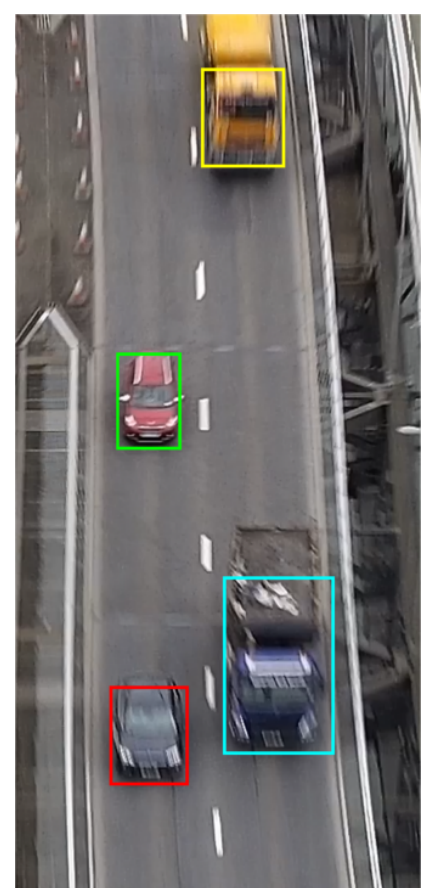

b)

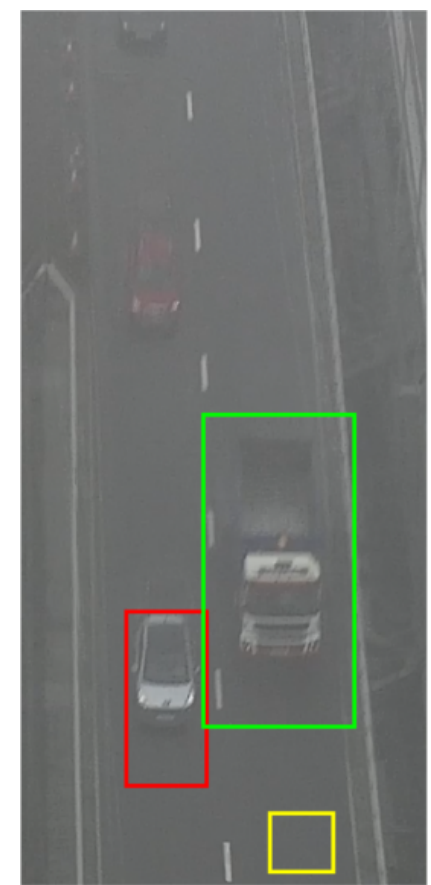

c)

Figure 6. Errors due to weather: a) sunny conditions; b) windy conditions;

c) foggy conditions.

\subsection{Field calibration}

The vehicle lengths extracted from images are initially measured in pixel units. Conversion factors are needed to convert these values into lengths in metres. Six different conversion factors (CF) are developed using the actual length (metres) and the measured length (pixels) between six half-joint beams. Figure 7 shows these six beams and their spacing in the image in pixel units. The interval distance between two half-joints is $9,063 \mathrm{~m}$. When a vehicle extends over a half-joint, it is separated into segments and the length of each segment calculated using a different CF. 
An additional correction is required to remove the additional length of the object that results from the vehicle height. After application of the correction factors, the distance $|\mathrm{DF}|$ in Figure 8 describes the vehicle length in metres. The true length of the vehicle is $|\mathrm{DE}|$. The difference, $|\mathrm{EF}|$, is found from similar triangles:

$|\mathrm{EF}|=|\mathrm{EG}| \cdot \frac{|\mathrm{BC}|+|\mathrm{CD}|+|\mathrm{DF}|}{|\mathrm{AB}|}$

where $|\mathrm{EG}|$ is the height of the vehicle, $|\mathrm{BC}|$ is the known hidden length, $|\mathrm{CD}|$ is the visible length in front of the vehicle, $|\mathrm{DF}|$ is the ground length of the vehicle and $|\mathrm{AB}|$ is the installation height of the camera. All of these lengths are known or can be found except vehicle height which is assumed to be $1.30 \mathrm{~m}$ for cars, $2.25 \mathrm{~m}$ for vans and $4.65 \mathrm{~m}$ for trucks, respectively. 
There are a number of sources of inaccuracy in the vehicle length calculation. While induction loops are also known to be inaccurate, they are used here to validate the data and apply a small correction to the lengths calculated from images. An additional camera on site has been used to record the vehicles crossing over the WIM system. For one hour of video of the traffic passing the WIM system vehicles are identified and the same vehicles are found in the tower camera images. Figure 9 shows two examples of the same vehicle identified in both videos. The length of the Truck 1 extracted from the Tower Camera image is $18.40 \mathrm{~m}$ while its length registered by the WIM system is $19 \mathrm{~m}$. The second truck has a length of $8.66 \mathrm{~m}$ extracted from Tower Camera image and $8.40 \mathrm{~m}$ recorded in the WIM system data.

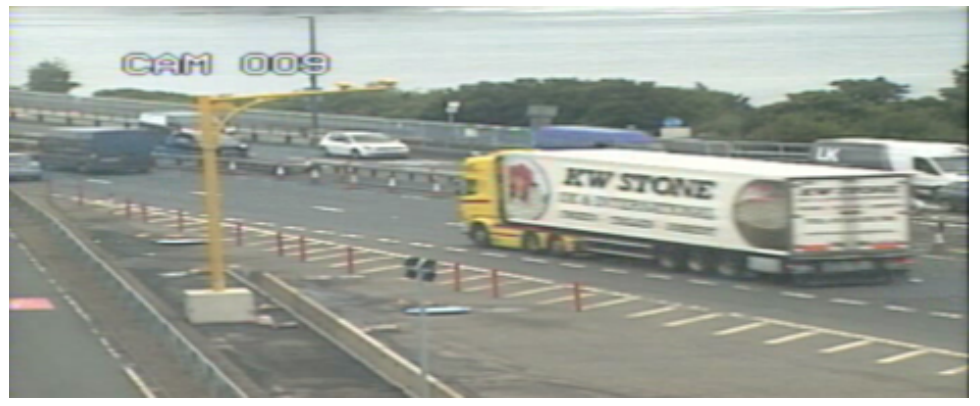

a)

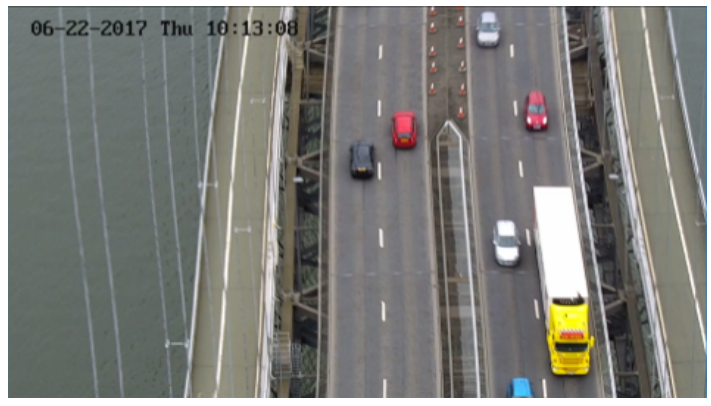

b) 


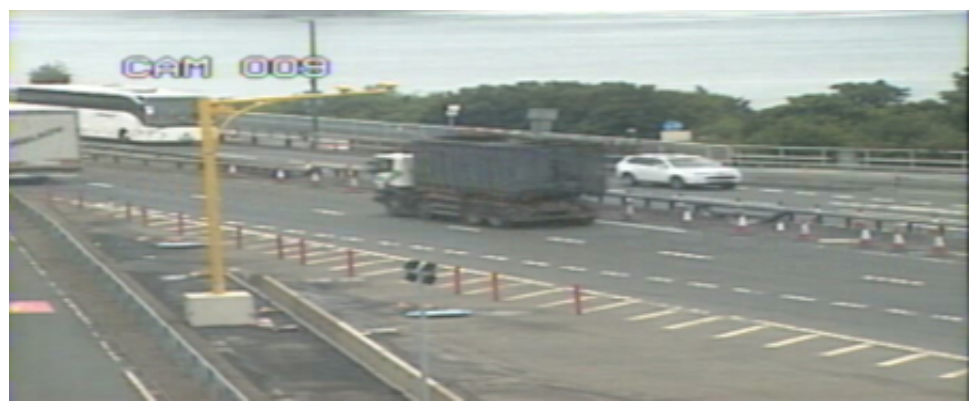

c)

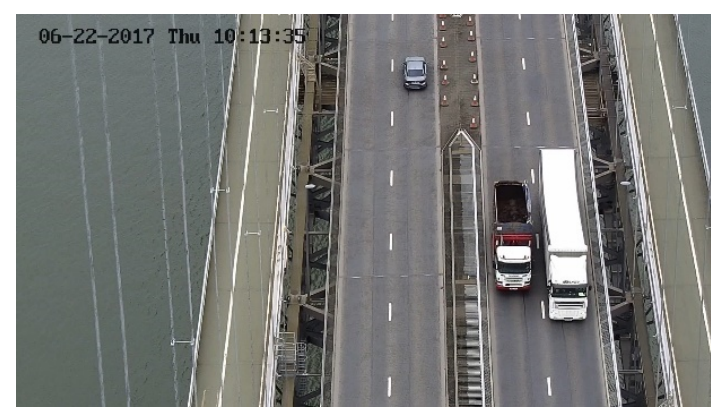

d)

Figure 9. Vehicle identification: a) Vehicle passing over the WIM system - truck 1; b) Truck 1 captured by the Tower Camera; c) Vehicle passing over the WIM system - truck 2;

d) Truck 2 captured by the Tower Camera.

Similar comparisons were performed for 200 trucks. Figure 10 illustrates the differences between truck lengths obtained from the Tower Camera images $\left(\mathrm{L}_{\mathrm{TOW}}\right)$ and their lengths registered by the WIM system $\left(\mathrm{L}_{\text {WIM }}\right)$. The dashed line is the best fit of the data and it is compared to the $45^{\circ}$ reference line which is illustrated as a continuous black line. There is significant variation in the individual vehicle lengths inferred by the two systems. From a statistical perspective, the bias in the population is the important parameter. Fortunately, this is small, with the best-fit relationship giving a 3\% bias:

$$
\mathrm{L}_{\mathrm{TOW}}=1.03 \cdot \mathrm{L}_{\mathrm{WIM}}-0.07
$$

On the basis that inductive loops, while imperfect, are an established technology, this correction is applied to the lengths inferred from the Tower Camera images. 
Figure 10. Comparison of lengths inferred from Tower Camera images and lengths from the WIM

$$
\text { system. }
$$

\section{Inferring weights from lengths}

A novel method that uses only vehicles lengths and a length/weight statistical correlation to estimate the extreme traffic events is proposed by the authors in [63] and implemented here for the Forth Road Bridge. WIM data records for northbound traffic are used in this study to establish the statistical relationship between length and weight. As vehicles in the fast lane are more likely to be empty, separate weight/length relationship is established for each lane. Almost one year of data for each lane is separated into 100 subdivisions, according to length, in increments of $0.3 \mathrm{~m}$. An example is presented in Figure 11 of the histogram for slow lane vehicles with length in the range $17.7-18 \mathrm{~m}$. For this length interval, the most frequent gross vehicle weight (GVW) is around $20 \mathrm{t}$. 
For each lane and length segment, the probability density function (PDF) is estimated by a univariate kernel density estimator (KDE) [64]. The resulting PDF and cumulative distribution function (CDF) for the $17.7-18 \mathrm{~m}$ segment in the slow lane, is illustrated in Figure 12. Monte Carlo simulation is used to generate a 'typical' weight from the CDF for each recorded Tower Camera vehicle length.

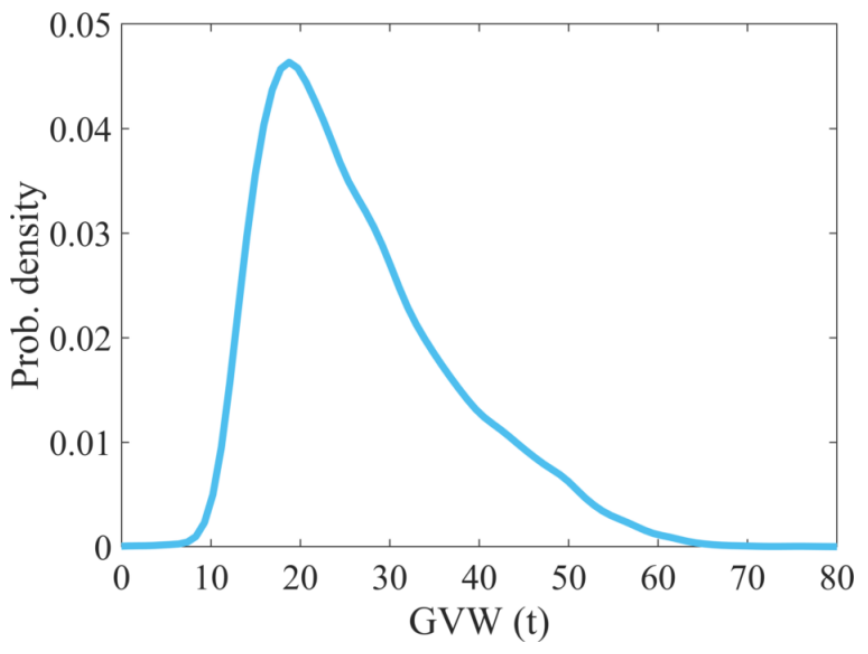

a)

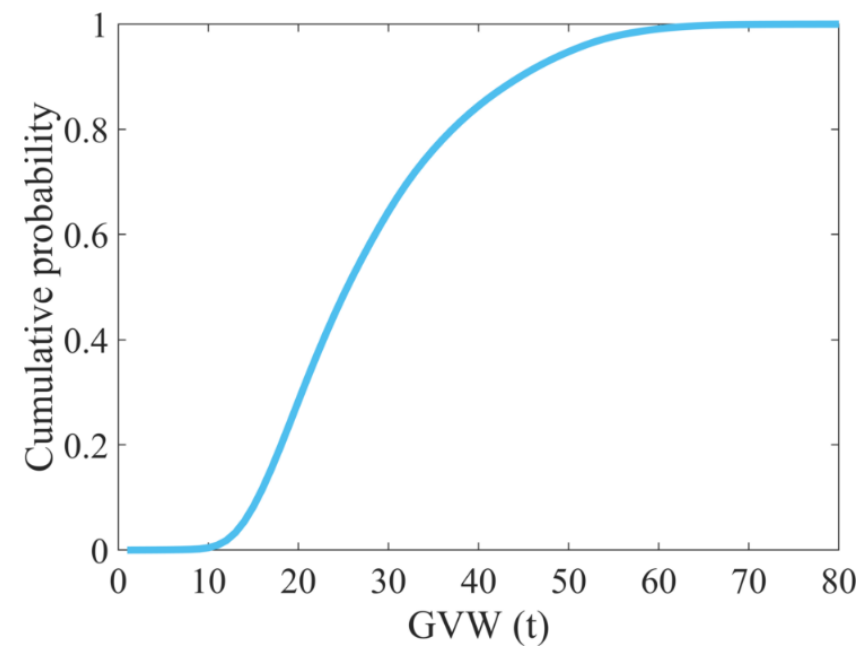

b)

Figure $12.60^{\text {th }}$ segment in slow lane $(17.7-18 \mathrm{~m})$ : a) PDF; b) CDF

\section{Traffic loading on the FRB}

\subsection{Traffic congestion}

As there was an insufficient quantity of congested traffic data, congestion is simulated in order to estimate extreme loading events and to illustrate the proposed approach. One thousand examples of 
congested traffic are induced by jamming the traffic on both the fast and slow lanes. The image data provide the vehicle lengths and their sequence (car/truck mix). A starting image is first selected randomly from the image database. The length data provided by this image and by the following images are stored until they occupy the total length of the bridge. The bumper-to-bumper gaps between vehicles are collapsed to a $1.5 \mathrm{~m}$ constant value [52]. In an alternative approach, a Beta-distribution is used to generate random inter-vehicle gap values according to vehicle type (car-car, car-truck, truckcar, truck-truck) [20]. For both the constant and random inter-vehicle gap cases, lane-changing may or may not be allowed. Thus, when it is not allowed, there are two cases: no lane changing with constant gaps (NLC-CG) and no lane changing with random gaps (NLC-RG). The prevention of lane changing may introduce errors in safety assessments as vehicles are known to change lane as traffic becomes congested [24] and this in turn influences load effect. Therefore, in an alternative approach, the freeflowing traffic is redistributed between the fast and slow lanes as congestion increases, by applying a set of lane-changing criteria. This approach compares the difference between the congested queue lengths in each lane and hence assigns a probability of lane changing. This creates two more cases: lane changing with constant gaps (LC-CG) and lane changing with random gaps (LC-RG). In the lane changing scenario, the congested queues build up as vehicles reach the bottleneck. The queue of congested traffic is usually longer in the slow lane due to the higher percentage of vehicles and trucks in this lane. An increased probability of lane changing occurs when the queue in the slow lane becomes longer than that in the fast lane. There is a lower probability that a truck will change lane as suggested by Rickets and Page [53]. This assumption increases the percentage of trucks and the length of truck platoons in the slow lane. Typical weights are inferred from the vehicle lengths as described in Section 4.

\subsection{Axial force in the main cable}

Axial force in the main cable is used here as an example of a long-span load effect. The influence lines (ILs) for the FRB cable force, for northbound traffic, are illustrated in Figure 13. 
For long-span bridges, it is highly unlikely that the traffic is fully stopped in both directions at the same time (it would require simultaneous accidents at the north end of the northbound carriageway and the south end of the southbound carriageway). Therefore, congestion is particularly assumed for the north direction while the south direction is governed by free-flowing traffic. The small contribution of the free-flowing traffic in the southbound direction to cable force on the northbound carriageway side, is not considered in this study. As the images cannot provide information about the number of axles, the weight of each vehicle is assumed as a point load, a reasonable approximation on such a long IL. Each vehicle weight is multiplied by the corresponding ordinate from the influence line graph - fast or slow lane - according to the position of the vehicle on the bridge. Afterwards, these values are summed separately for the fast and slow lanes and combined.

\subsection{Characteristic value for axial force}

The values for axial force in the main cable are plotted in Figure 14 on a Gumbel probability paper plot [65]. The linearity of the data indicates a good fit to the Gumbel distribution [66]. To facilitate comparison to the Eurocode and AASHTO codes, the extreme values [67, 68] are determined for 1000-year and 75-year return periods $[69,70]$. Assuming there are four jams (i.e. accidents) per year, 

typical for this bridge, the probability that an event might occur once in the return period is 1 $1 /(4 \times 1000)=0.9998($ Eurocode $)$ or $1-1 /(4 \times 75)=0.9967($ AASHTO $)$. The characteristic axial force due to traffic in one direction only is extrapolated from a simulation of 250 years (1000 independent jams). Hence, the site-specific characteristic values for each assumption are calculated and presented in Table 1.

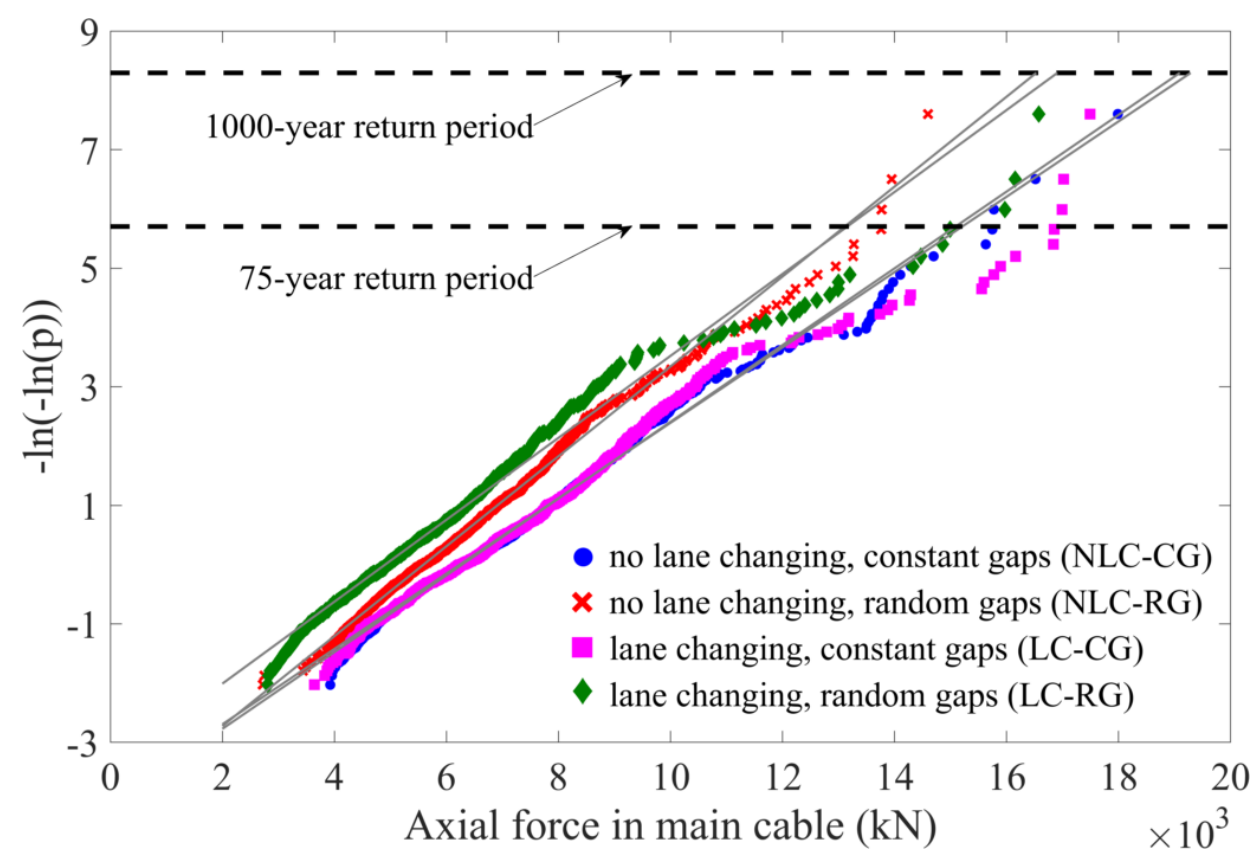

Figure 14. Gumbel probability paper plot, where $\mathrm{p}$ is the probability of non-exceedance.

Table 1. Characteristic maximum axial force and corresponding code values $(\times 1000 \mathrm{kN}) . \mathrm{LC}=$ Lane Changing, NLC $=$ No Lane Changing.

\begin{tabular}{l|cc|cc}
\hline & \multicolumn{2}{|c|}{ Random gaps } & \multicolumn{2}{c}{ Constant gaps } \\
\cline { 2 - 5 } & NLC & LC & NLC & LC \\
\hline 75-year return period & 13.1 & 13.2 & 15.1 & 15.2 \\
\hline AASHTO HL93 & 55.0 & 55.0 & 55.0 & 55.0 \\
\hline 1000-year return period & 16.5 & 16.9 & 19.1 & 19.3 \\
\hline Eurocode $\left(\alpha_{i}=1\right)$ & 32.0 & 32.0 & 32.0 & 32.0 \\
\hline Eurocode $($ UK) & 32.4 & 32.4 & 32.4 & 32.4 \\
\hline
\end{tabular}

There is $1 \%$ to $2.5 \%$ difference between the lane-changing and no-lane-changing cases, perhaps small due to the small percentage of trucks in the data. Nevertheless, this suggests that the results are not strongly influenced by the lane changing assumption. At this site vehicles are distributed in a balanced manner between lanes which means that congested queues have similar lengths and the probability of changing lane is low. There are significant differences between results from the random and constant 

gap assumptions. The Beta distribution allows greater distances between vehicles which results in characteristic values about $13 \%$ less.

Neither the AASHTO [71] nor the Eurocode [72] load models are intended or applicable for long-span bridges. However, in the absence of an alternative, they serve as interesting reference points. Imposing the AASHTO HL93 model to the influence line results in a contribution from the northbound carriageway traffic to cable force of 55,000 kN (Table 1), 4 times greater than the characteristic 75year value on the FRB. The standard Eurocode Load Model 1, with all $\alpha$-factors taken at the default values of unity, gives a contribution to cable force of $32,000 \mathrm{kN}, 2$ times greater than the characteristic 1000-year value. The UK national annex to the Eurocode recommends $\alpha$-factors of 0.61 for lane 1 and 2.2 for other lanes. This increases the contribution to axial force to $32,400 \mathrm{kN}$, considerably more conservative.

\section{Summary and conclusions}

This paper presents a novel approach to the process of estimating site-specific characteristic maximum load effects on the FRB using vehicle length data only. Standard image processing techniques are used to analyse five months of traffic image data and extract the vehicle lengths. A WIM database consisting of one year of free-flowing traffic data were used to develop a statistical correlation between vehicle lengths and weights. Length/weight correlation is then used to infer weights from lengths in images. The traffic in images is then jammed to create congestion and the axial force in one of the main cables is evaluated using the corresponding influence lines. The influence of some key assumptions is investigated: constant versus random values for inter-vehicle gaps and lane-changing versus the stay-in-lane assumption. The results of 250 years of simulations follow a Gumbel distribution. The characteristic values corresponding to probabilities of non-exceedance of 75 -years and 1000-years are calculated. The results show that, for this site, characteristic load effects are not sensitive to the lane-changing assumption. On the other hand, the Beta distribution used to simulate random gaps has a significant effect on the results. Comparison of these results with the corresponding 
values specified in the Eurocode and AASHTO shows, unsurprisingly, that the codes are highly conservative. It is concluded that lengths extracted from traffic image data provide a valuable means of calculating load effects in long-span bridges.

\section{Acknowledgments}

The authors would like to acknowledge the support received from Science Foundation Ireland under US/Ireland Programme Grant 14/US/I3033. Transport Scotland is also gratefully acknowledged. The authors would also like to thank Ms. Shruthi Ramprakash for her assistance with the data analysis.

\section{References}

[1] M. M. Attard, M. G. Stewart, 'A two parameter stress block for high-strength concrete', ACI Structural Journal 95(3) (1998) 305-317.

[2] M. S. Darmawan, M. G. Stewart, 'Spatial time-dependent reliability analysis of corroding pretensioned prestressed concrete bridge girders', Structural Safety 29(1) (2007) 16-31.

[3] D. Pines, A. E. Aktan, 'Status of structural health monitoring of long-span bridges in the United States', Structural Engineering and materials 4(4) (2002) 372-380.

[4] M. G. Stewart, 'Reliability-based assessment of ageing bridges using risk ranking and life cycle cost decision analyses', Reliability Engineering \& System Safety 74(3) (2001) 263-273.

[5] M. G. Stewart, D. V. Val, 'Role of load history in reliability-based decision analysis of aging bridges', Journal of Structural Engineering - ASCE 125(7) (1999) 776-783.

[6] C. Carey, E. J. OBrien, A. Malekjafarian, M. Lydon, S. Taylor, 'Direct field measurement of the dynamic amplification in a bridge', Mechanical Systems and Signal Processing 85 (2017) 601-609.

[7] C. C. Caprani, 'Using microsimulation to estimate highway bridge traffic load', Proc. 5th Intl. Conf. on Bridge Maintenance, Safety and Management, 2010.

[8] A. Paeglitis, A. Freimanis, 'Comparision of Constant-Span and Influence Line Methods for Long-Span Bridge Load Calculations', Baltic Journal of Road and Bridge Engineering 11(1) (2016) 84-91.

[9] A. S. Nowak, T. Tharmabala, 'Bridge Reliability Evaluation Using Load Tests', Journal of Structural Engineering-Asce 114(10) (1988) 2268-2279.

[10] A. Getachew, 'Traffic load effects on bridges, statistical analysis of collected and Monte Carlo simulated vehicle data', $\mathrm{PhD}$ Thesis, Royal Institute of Technology, Stockholm, Sweden, 2003.

[11] E. S. Hwang, K. T. Lee, D. Y. Kim, 'Modeling of truck traffic for long span bridges', Bridge Maintenance, Safety, Management, Resilience and Sustainability (2012) 1100-1107.

[12] M. Lutomirska, 'Live load models for long span bridges', Civil Engineering, University of Nebraska, Lincoln, Nebraska, 2009.

[13] A. S. Nowak, M. Lutomirska, F. I. Sheikh Ibrahim, 'The development of live load for long span bridges', Bridge Structures 6(1, 2) (2010) 73-79. 
[14] G. Sedlacek, G. Merzenich, M. Paschen, A. Bruls, L. Sanpaolesi, P. Croce, J. A. Calgaro, M. Pratt, M. Leendertz Jacob, v. de Boer, A. Vrouwenfelder, G. Hanswille, 'Background document to EN 1991-Part 2-Traffic loads for road bridges-and consequences for the design', JRC_European Commission, 2008.

[15] C. C. Caprani, E. J. OBrien, 'The governing form of traffic for highway bridge loading', in: E. Cannon, R. West, P. Fanning (Eds.) Proceedings of 4th Symposium on Bridge and Infrastructure Research in Ireland, National University of Ireland, Galway, 2008, 53-60.

[16] A. F. Al-Kaisy, F. L. Hall, E. S. Reisman, 'Developing passenger car equivalents for heavy vehicles on freeways during queue discharge flow', Transportation Research Part a-Policy and Practice 36(8) (2002) 725-742.

[17] F. Moses, 'Weigh-in-Motion System Using Instrumented Bridges', Transportation Engineering Journal - ASCE 105(3) (1979) 233-249.

[18] E. J. OBrien, A. Znidaric, T. Ojio, 'Bridge weigh-in-motion-Latest developments and applications world wide', Proceedings of the International Conference on Heavy Vehicles, John Wiley, Paris, France, 2008, 19-22.

[19] E. J. OBrien, A. Lipari, C. C. Caprani, 'Micro-simulation of single-lane traffic to identify critical loading conditions for long-span bridges', Engineering Structures 94 (2015) 137-148.

[20] S. F. Bailey, 'Basic principles and load models for the structural safety evaluation of existing road bridges', Civil Engineering, Ecole Polytechnique Fédérale de Lausanne, Lausanne, 1996.

[21] A. Bruls, P. Croce, L. Sanpaolesi, G. Sedlacek, 'ENV 1991-Part 3: Traffic loads on bridges Calibration of road load models for road bridges', IABSE REPORTS: Basis of design and actions on structures; Background and application of Eurocode 1, Delft, 1996, 439-454.

[22] P. G. Buckland, J. P. McBryde, F. P. Navin, J. V. Zidek, 'Traffic loading of long span bridges', Bridge Engineering 2(665) (1978).

[23] P. G. Buckland, 'North-American and British Long-Span Bridge Loads', Journal of Structural Engineering - ASCE 117(10) (1991) 2972-2987.

[24] A. A. Hayrapetova, A. J. O’Connor, E. J. OBrien, 'Traffic Load Models for Long Span Bridges', Bridge Maintenance, Safety, Management, Resilience \& Sustainability, Taylor \& Francis Group, Stresa, Italy, 2012, 2589-2596.

[25] E. J. OBrien, A. Hayrapetova, C. Walsh, 'The use of micro-simulation for congested traffic load modeling of mediumand long-span bridges', Structure and Infrastructure Engineering 8(3) (2012) 269-276.

[26] O. Ditlevsen, 'Traffic Loads on Large Bridges Modeled as White-Noise Fields', Journal of Engineering Mechanics 120(4) (1994) 681-694.

[27] A.C.W.M. Vrouwenvelder, P.H. Waarts, 'Traffic loads on bridges', Structural Engineering International 3(93) (1993) $169-177$.

[28] K. Aghabayk, M. Sarvi, W. Young, 'Understanding the Dynamics of Heavy Vehicle Interactions in Car-Following', Journal of Transportation Engineering - ASCE 138(12) (2012) 1468-1475.

[29] A. F. Al-Kaisy, Y. Jung, H. Rakha, 'Developing passenger car equivalency factors for heavy vehicles during congestion', Journal of Transportation Engineering - ASCE 131(7) (2005) 514-523.

[30] P. Ferrari, 'The Effect of Driver Behavior on Motorway Reliability', Transportation Research Part B-Methodological 23(2) (1989) 139-150.

[31] H. Yoo, P. Green, Driver behavior while following cars, trucks, and buses, The University of Michigan Transportation Research Institute, 2009.

[32] R. A. Shabih, K. M. Kockelman, 'Effect of vehicle type on the capacity of signalized intersections: the case of lightduty trucks', Journal of Transportation Engineering-Asce 126(6) (2000) 506-512. 
[33] Stefan Krauß, 'Microscopic modeling of traffic flow: Investigation of collision free vehicle dynamics', 1998.

[34] C. C. Caprani, E. J. OBrien, A. Lipari, 'Long-span bridge traffic loading based on multi-lane traffic micro-simulation', Engineering Structures 115 (2016) 207-219.

[35] B. S. Kerner, 'The physics of traffic', Physics World 12(8) (1999) 25-30.

[36] W. S. Vickrey, 'Congestion Theory and Transport Investment', Papers and proceedings of the eighty-first annual meeting of the American economic association, American Economic Association, 1969, 251-260.

[37] M. Treiber, A. Hennecke, D. Helbing, Microscopic simulation of congested traffic, in: D. Helbing, H.J. Herrmann, M. Schreckenberg, D.E. Wolf (Eds.), Traffic and granular flow'99, Springer Berlin Heidelberg2000, 365-376.

[38] B. Enright, C. Carey, C.C. Caprani, 'Microsimulation Evaluation of Eurocode Load Model for American Long-Span Bridges', Journal of Bridge Engineering 18(12) (2013) 1252-1260.

[39] C. C. Caprani, 'Calibration of a Congestion Load Model for Highway Bridges Using Traffic Microsimulation', Structural Engineering International 22(3) (2012) 342-348.

[40] L. A. Klein, M. K. Mills, D. R. P. Gibson, Traffic Detector Handbook: -Volume II, Third ed., Federal Highway Administration, MacLean, VA2006.

[41] J. Treiterer, J. Myers, 'The hysteresis phenomenon in traffic flow', 6th International Symposium on Transportation and Traffic Theory, Buckley, D.J., 1974, 13-38.

[42] B. Coifman, D. Beymer, P. McLauchlan, J. Malik, 'A real-time computer vision system for vehicle tracking and traffic surveillance', Transportation Research Part C - Emerging Technologies 6(4) (1998) 271-288.

[43] Y. N. Chen, C. C. Han, G. F. Ho, K. C. Fan, 'Facial/License Plate Detection Using a Two-level Cascade Classifier and a Single Convolutional Feature Map', International Journal of Advanced Robotic Systems 12(12) (2015) 183.

[44] L. Wang, F. L. Chen, H. M. Yin, 'Detecting and tracking vehicles in traffic by unmanned aerial vehicles', Automation in construction 72 (2016) 294-308.

[45] J. Xu, G. Wang, F. Sun, 'A novel method for detecting and tracking vehicles in traffic-image sequence', Fifth International Conference on Digital Image Processing (ICDIP 2013), International Society for Optics and Photonics, 2013, 88782P.

[46] G. H. Zhang, R. P. Avery, Y. H. Wang, 'Video-based vehicle detection and classification system for real-time traffic data collection using uncalibrated video cameras', Transportation Research Record (1993) (2007) 138-147.

[47] B. Morris, M. Trivedi, 'Robust classification and tracking of vehicles in traffic video streams', Intelligent Transportation Systems Conference, 2006. ITSC'06. IEEE, 2006, 1078-1083.

[48] Yu Peng, Jesse S Jin, Suhuai Luo, Min Xu, Yue Cui, 'Vehicle type classification using PCA with self-clustering', Multimedia and Expo Workshops (ICMEW), 2012 IEEE International Conference, 2012, 384-389.

[49] P. Reinartz, M. Lachaise, E. Schmeer, T. Krauss, H. Runge, 'Traffic monitoring with serial images from airborne cameras', ISPRS Journal of Photogrammetry and Remote Sensing 61(3-4) (2006) 149-158.

[50] G. Farnebäck, K. Nordberg, 'Motion detection in the WITAS project', Swedish Symposium on Image Analysis (SSBA), Lund, , 2002, 99-102.

[51] T. Fu, S. Zangenehpour, P. St-Aubin, L. P. Fu, L. F. Miranda-Moreno, 'Using microscopic video data measures for driver behavior analysis during adverse winter weather: opportunities and challenges', Journal of Modern Transportation 23(2) (2015) 81-92.

[52] P. G. Buckland, F. P. D. Navin, J. V. Zidek, J. P. McBryde, 'Proposed vehicle loading of long-span bridges', Journal of the Structural Division 106(4) (1980) 915-932.

[53] NJ Ricketts, J Page, 'Traffic data for highway bridge loading', TRL REPORT 251 (1997). 
[54] E. A. Micu, E. J. OBrien, E. Sevillano, 'Application of image processing to the analysis of congested traffic', in: J. Goggins (Ed.) Proceedings of Civil Engineering Research in Ireland, Galway, 2016, 317-320.

[55] R. McKinstray, E. Angus, E. J. OBrien, E. A. Micu, A. Malekjafarian, M. Lydon, 'Image data for bridge traffic load monitoring on Forth Road Bridge', in: M.C. Forde (Ed.) 17th European Bridge Conference, Edinburgh, Scotland, , 2018.

[56] B. Sivakumar, F. I. Sheikh Ibrahim, 'Enhancement of bridge live loads using weigh-in-motion data', Bridge Structures 3(3-4) (2007) 193-204.

[57] B. Enright, 'Simulation of traffic loading on highway bridges', School of Architecture, Landscape and Civil Engineering, University College Dublin, Ireland, 2010.

[58] N. Otsu, 'A threshold selection method from gray-level histograms', IEEE transactions on systems, man, and cybernetics 9(1) (1979) 62-66.

[59] L. Vincent, 'Morphological grayscale reconstruction in image analysis: Applications and efficient algorithms', Transactions on Image Processing - IEEE 2(2) (1993) 176-201.

[60] D. Cáceres Hernández, L. Kurnianggoro, A. Filonenko, K. H. Jo, 'Real-time lane region detection using a combination of geometrical and image features', Sensors 16(11) (2016) 1935.

[61] D. Bradley, G. Roth, 'Adaptive thresholding using the integral image', Journal of graphics tools 12(2) (2007) 13-21.

[62] E. A. Micu, R. McKinstray, E. Angus, E. J. OBrien, A. Malekjafarian, M. Lydon, 'Estimation of traffic load effects on Forth Road Bridge using camera measurements', in: V. Pakrashi, J. Keenahan (Eds.) Civil Engineering Research in Ireland 2018 (CERI2018), Civil Engineering Research Association of Ireland, Dublin, Ireland, 2018, 79-83.

[63] E. A. Micu, E. J. OBrien, A. Malekjafarian, M. Quilligan, 'Estimation of extreme traffic loading using vehicle length for long-span bridges', Baltic Journal of Road and Bridge Engineering (In Press) (2018).

[64] M. C. Jones, R. F. Kappenman, 'On a Class of Kernel Density Estimate Bandwidth Selectors', Scandinavian Journal of Statistics 19(4) (1992) 337-349.

[65] J. Chambers, W. Cleveland, B. Kleiner, P. Tukey, Graphical Methods for Data Analysis, Wadsworth1983.

[66] J. R. Benjamin, C. A. Cornell, Probability, statistics and decision for civil engineers, McGraw-Hill, New York, 1970.

[67] E. Castillo, Extreme value theory in engineering, Academic Press, New York, 1988.

[68] B Jacob, 'Methods for the Prediction of Extreme Vehicular Loads and Load Effects on Bridges Report of Subgroup 8, Eurocode 1', Traffic Loads on Bridges Paris, France: Laboratoire Central des Ponts et Chaussées, LCPC (1991).

[69] E. J. OBrien, B. Enright, A. Getachew, 'Importance of the Tail in Truck Weight Modeling for Bridge Assessment', ASCE Journal of Bridge Engineering 15(2) (2010) 210-213.

[70] C. Cremona, 'Optimal extrapolation of traffic load effects', Structural Safety 23(1) (2001) 31-46.

[71] American Association of State Highway and Transportation Officials., 'AASHTO LRFD Bridge Design Specifications - Fifth edition', American Association of State Highway and Transportation Officials, Washington, 2010.

[72] EC1.2., '2 Eurocode 1: Actions on Structures-Part 2: Traffic Loads on Bridges', European Standard EN 1991-2: European Committee for Standardisation, Brussels, 2003. 